\title{
THE STRUGGLE FOR RECOGNITION AND THE POLITICS OF IDENTITY: A FEMINIST JURISPRUDENTIAL APPROACH TO PRESIDENT OF THE REPUBLIC OF SOUTH AFRICA V HUGO
}

\author{
by Amit Parekh*
}

Introduction

Equity feminism characterised by an almost egalitarian idealism, raises an irreconcilable paradox: is it possible to be egalitarian or profess to be fighting for equality when presenting a view of the world solely from a woman's perspective; impoverished from the very thing it desires? It is this ideological framework under which this paper seeks to redress the majority judgment made in President of the Republic of South Africa $v$ Hugo.

\section{$2 \quad$ Facts and judgment}

In President of the Republic of South Africa $v$ Hugo, ${ }^{1}$ the then South African President granted a remission of prison sentences in respect of all imprisoned mothers who had minor children below the age of 12 years old. This was in terms of the Presidential Pardon Act 17 of 1994. The Constitutional Court ruled that the Act did not amount to unfair discrimination against imprisoned fathers of minor children.

\section{The struggle for recognition and the politics of identity}

Two approaches to law, feminist legal theory and critical race theory are sometimes considered together under the label 'outsider jurisprudence' because they can both be seen as emanating from the same core problem: "[t]he extent to which the law reflects the perspective of and the values of white males and the resulting effects on citizens and on members of the legal profession who are not white males'. 2

This therefore highlights the defining premise of the contemporary feminist theory - that is, that we live in 'a maledominated culture', and that the feminist agenda as well as the goal

* $\quad$ LLB (UP), candidate attorney, Bowman Gillfillan Attorneys. I wish to thank Proff Christo Botha and Karin van Marle for their support and encouragement.

119974 SA 1 (CC).

2 S Brewer 'Introduction: Choosing sides in the racial critique debate' 103 Harvard Law Review 1850-1851. 
of the feminist jurisprudence is not equal treatment of all 'persons', but redistribution of power and assets from the 'oppressor class' (men) to the 'oppressed class' (women), thereby stripping men of their rights, so as to 'equalise' the 'power disparity' they claim exist.

Even 'equity feminism' (or commonly referred to as the 'second wave feminism'), which seeks to be distinguished (from its other ideological counterparts) as egalitarian, raises an irreconcilable paradox - an oxymoron on the grandest scale: it is impossible to be egalitarian or to profess fighting for equality when presenting a view of the world solely from women's perspective. It is this very ideological framework under which this paper seeks to redress the majority judgment in the case of President of the Republic of South Africa and Another $v$ Hugo.

In light of the convictions made by feminist proponents, consideration must consequently be given to societal pressure placed upon men in traditional popular culture. The ensuing result of such a miss-conceptualisation about men has been always to keep a stiff upper lip through the repression of deeply-seated emotions - thus obviating the chances of exposing oneself to vulnerability; thereby causing considerably higher suicide rates and cases of depression and other psychiatric phenomena.

Further, whilst feminism seeks to remove itself from its own and super-imposed male ideological shackles, many proponents often lose sight of the fact that men, so too, gain sexual hegemony through the reinforcement of the mytho-anthropological hunter-gatherer scenarios of men risking their lives for their family, whose domestic life is managed by women. Since fathers transmit their views of life to their sons, a strict political-economic order is maintained - thus marginalising the rights of single fathers in contexts in which men are the sole breadwinners.

However, as will be elucidated below in my analysis of the Hugo case, it must be determined whether or not the stereotypes entrenched amongst civil society, in which men should never be seen or heard to complain or feel ashamed if victimised by a female partner or wife, have been swept under the dark recesses of society's heavily interweaved carpet - tainted by stains and spillages of deeplyseated stigmas, associations and ideological fallacies.

It is the author's contention, therefore, that by reinforcing such stereotypes, to which Kriegler J dissents in his judgment, men are not allowed to 'compete' with women for the status of societal 'victims,' as men are conditioned to be responsible (traditionally seen as the primitive hunter-gatherer and protector) so they automatically 'lose'.

Placing this in the context of Hugo, with the resultant finding that the remissions of 440 female prisoners as opposed to no remission for male prisoners is not unfair discrimination, despite the judgment 
being based upon an often-misconstrued, misappropriated and outdated stereotype ${ }^{3}$ of women bearing sole child-rearing duties. In this way, it is my contention that such an assertion by liberal feminists rejects any possible claim by proponents of the Queer Theory - one which focuses upon the capabilities and rights of gay men to foster an environment which is capable for the healthy upbringing of children. ${ }^{4}$

In this way, the postmodernist questioning of what it means to be a '(wo)man' is brought to a brilliant intellectual crescendo. ${ }^{5}$

Feminists assert that history was written from a male point of view and does not reflect women's role in making history and structuring society. 'Male-written history has created a bias ${ }^{6}$ in the concepts of human nature, gender potential, and social arrangements ${ }^{7}$ of which men and women must stereotypically adhere to. Such a contention is no more apparent than in the language, logic and structure of the majority judgment in Hugo in which male values are reinforced, and which at the same time denies men any chance of ever receiving parental rights on the basis of equality.

By presenting male characteristics as a 'norm' and female characteristics as a deviation from the 'norm', prevailing conceptions of law reinforce and perpetuate patriarchal power.

However, in the Hugo case, the contrary seemed more apparent, the very notion that: 'women are to be regarded as primary caregivers of young children is a root of inequality in our society ... relegates women to a subservient occupationally inferior yet increasingly onerous role'. ${ }^{8}$

This highlights that it is not the celebrated patriarch who holds women to such a role, but rather the women in casu who, in seeking such remission, rely on a stereotype. It may be said therefore that the assertion that such stereotypical denigration is all too often not necessarily perpetrated by the hands of men, but rather women; women who often complacently fall upon such a role as their Godgiven duty, thereby necessitating their release: '... the benefits in this case are to a small group of women - the 440 released from prison

$3 \quad$ Hugo (n 1 above) 37B.

4 C Albertyn 'Feminism and the law' in C Roederer \& D Moellendorf (eds) Jurisprudence (2004) 308, where it has been argued that the 'radical assumption that gender is the sole or dominant form of oppression has masked other inequalities such as race, class or sexual orientation'.

See in this regard V Woolf's Orlando.

6 This is of fundamental concern for liberal feminists who "challenge the content rather than the form of the law' - a duality challenged by postmodernism which sees the eradication of gender bias not indispensable to 'neutral and impartial institutions'.

7 'Feminist jurisprudence' http://www.law.cornell.edu/wex/index.php/Feminist_ jurisprudence (accessed 24 June 2007).

8 Hugo (n 1 above) 37B-C. 
- and the detriment is to all South African women who must continue to labour under the social view that their place is in the home'.

In this way, the prejudicial implications of sexual subservience are not only cast upon by the bench in their reinforcement of patriarchal values, but the women in question - who like anyone regardless of their sex - could have asked that each case be weighed on its merits, thereby looking at the women's subjective experiences and realities as women and not as child-bearers capable only of fulfilling maternal duties and not self-actualisation. Rather, as will be contended, the court simply cast upon them (and consequently men) a baby blanket dampened by the stench of generalisation of short-sightedness.

Feminists challenge the belief that the biological make-up of men and women is so 'different that certain behaviour can be attributed on the basis of sex'. Gender, feminists say, is created 'socially, not biologically'. ${ }^{10}$ Sex determines such matters as physical appearance and reproductive capacity, 'but not psychological, moral, or social traits'. Is it therefore not contradictory, as purported in the majority judgment in the Hugo case, that women, stereotypically speaking, are the ones who bear child-rearing responsibilities?

If gender is simply an ideological construct by society, then why are male inmates subjected to judicial scrutiny through separate and independent applications which are scrutinised further through means testing in which to prove their child rearing capabilities and women not? Is this not reinforcing patriarchal stereotypes? Ultimately, this highlights, perhaps pre-emptively, the sameness-difference debate (which will be engaged with further) where in this case both men and women are incarcerated for the 'same' reason - their conduct whether directly or indirectly - contravened state law and thus they are both, regardless of the sex or gender, subject to sanctions.

Why, then, should women be treated differently when they in fact are incarcerated for the same fundamental reason? To my mind, therefore, such an implicit understanding of such a proposition as propounded in the Hugo judgment contradicts the very foundation on which the rule of law is based, further enshrining gender-based distinctions in both legal theory and practice. ${ }^{11}$

This in the author's opinion highlights a severe discrepancy in feminist theory - the irreconcilable difference of what is written and discussed in long corridors of academia, and what happens in practice when male and female rights are invariably pitted against one another.

$9 \quad$ Hugo (n 1 above) 38D.

10 n 7 above.

11 Albertyn (n 4 above) 292. 
Thus, if sex only serves scientific purposes, socially and morally speaking, men are just as, if not more, capable of attending to the responsibilities of child maintenance. Recent trends in family law, for example, highlight such an assertion in that the overwhelming population of men who find themselves in custody disputes pay child support for children they have not and will not see. ${ }^{12}$

Such a state of affairs is abhorrent and begs the question whether or not there exists institutionalised bias by members of the judiciary, as in the Hugo case, who still continue through their judgments to reinforce the patriarchal stereotype of which feminists seek to rid themselves, which is that they are the only ones capable of childrearing duties, thereby perpetuating perceptions relating to maternal duty, and not the fathers who have been biologically, emotionally and spiritually instrumental in the creation of the child, but who is now simply seen as an omniscient financial transaction which occasionally may take a human form and be 'lent' to him for a weekend or during the school holidays. To my mind, therefore, the sentimentality often accorded to 'the best interests of the child' is simply a homage to women clad in political correctness, as often, according to judges, the best interests of the child is that their custody be awarded to their mother. ${ }^{13}$

This highlights my contention that mothers are not given rights to their children because of their personal disposition to empathy and support, but because of heavily entrenched constructs purported by the majority of society. In other words, the women in Hugo are not given a remission of sentence because they are capable, enduring mothers but because, quite simply, they are women. In this way, the reasonable person could quite simply assert that such a justification for the remission is blatantly discriminatory.

This point was also poignantly elucidated by Kriegler J, who contended that the

President nowhere mentioned that it was his purpose to benefit women generally or the release of mothers in particular. There is no suggestion of compensation for wrongs of the past or an attempt to make good past discrimination against women. On the contrary, the whole thrust of the President's affidavit for the main supporting affidavit is the interests of the children. The third category of prisoners released under the Act was not women in their own right but solely in their capacity as perceived child minders.

12 See Fraser v Childrens Court, Pretoria North \& Others 19972 SA (CC) para 261 in respect of a provision of the Child Care Act which dispensed with the father's consent in the adoption of his illegitimate child. This section was found to constitute unfair discrimination.

13 See Van der Linde $v$ Van der Linde 19963 SA 509 (0) 515A-B, where the maternal preference rule is closely scrutinised; and Madiehe $v$ Madiehe 1997 [2] All SA 153 (B) $157 \mathrm{~F}-\mathrm{G}$, where such a principle was rejected. 
Thus, in the Hugo case, the 440 women themselves, in terms of their application under the Act, rely upon such a stereotypical construct - which then begs the question, who is reinforcing the entrenchment? Is it men? Or is it the women in casu who relied upon such an ideological premise?

Even if we accept that women have assumed this role because of societal conditioning, this would highlight another discrepancy in feminist discourse, namely that women are free autonomous individuals with the capacity to make meaningful choices, which govern their lives. Thus, the notion of the 440 women relying upon such a stereotypical construction negates such an argument by proponents of equity feminism. ${ }^{14}$

It is my view that, whilst men are to be blamed by some for the repression of women and their subsequent relegation to sexual subservience, in the twenty-first century there exists a misguided animosity towards all men as being chauvinistic bigots. What feminists must reappraise, instead, is whether they wish to be seen as individual and autonomous beings capable of making choices with their own implications without being tested against the controversial reasonable 'man', or do they wish, as in the Hugo case, to rely upon self-perpetuated ideologies of women as child bearers? I am by no means implying that women should therefore be forced to choose between their careers and their children, but this choice is common place. The title of child-bearer and 'maternal deity' is therefore often used and manipulated in what I believe to be the wrong contexts.

The act of being a mother, according to feminist discourse, has always been seen as a demeaning and unworthy profession. If (wo)men change their perception to such a position, then perhaps some of the social connotations of being such a contributory member of society may subside. However, as long as men and women perceive being a stay-at-home mom as an intellectually and physically inferior task, (wo)men will forever entrench their own social demise. Again, this point is emphasised by Kriegler $\mathrm{J}$ who states: 'Reliance on the generalisations that women are primary care givers is harmful in its tendency to cramp and stunt the efforts of men and women to form their identities freely.' 15

Though feminists share common commitments to notions of women's equality with men (how much is often ambiguous), feminist jurisprudence is not uniform in its construction of the importance and/or relevance to the female rights discourse. There are three

14 Post-modern jurisprudence sees this disposition as a resultant effect of the way scholars and legal discourse have portrayed women. See in this regard C Smart Feminism and the power of law (1989). 
major schools of thought within feminist jurisprudence. Traditional feminists assert that women are just as rational as men and therefore should have an equal opportunity to make their own choices. Liberal feminists challenge the assumption of male authority and seek to erase gender-based distinctions recognised by law, thus enabling women to compete in the marketplace. What strikes me as ironic, however, is that by seeking to extinguish the primitive flames of gender-based distinctions in terms of women's rights, the invariable consequences is the creation, as highlighted in Hugo, of further gender-based distinctions which reaffirm male inadequacy in child rearing and maintenance.

Another school of feminist legal thought, cultural feminists, 'focuses on the differences between men and women and celebrates those differences'. ${ }^{16}$ This group of thinkers asserts that 'women emphasise the importance of relationships, contexts, and reconciliation of conflicting interpersonal positions, whereas men emphasise abstract principles of rights and logic'. ${ }^{1}$

The goal of this school is to give 'equal recognition to women's moral voice of caring and communal values'. ${ }^{18}$ However slightly embittered, how is it possible to celebrate such differences when such difference is what impugns gender-based discrimination and ideological loggerheads? The question which ensues therefore is that, in light of common characteristics of both sexes and genders, is it possible to deliver a judgment which is free from stereotypical generalisations? Or is it that the judges are removing themselves from the position of mechanical operators, and instead are heightening their argument on (arguably subjective) moral pedestals? Surely then one must question the very foundation, historically speaking, of such generalisations.

Such an insight may be gleaned through the employing of the deconstructionist methodology by postmodernist Jacques Derrida, ${ }^{19}$ arguing that from the earliest age women are raised with the belief that their ideal character is one that is the opposite to that of men, not self-willed and governed by self-control, but of submission and yielding to the control of others. ${ }^{20}$ Moellendorf (eds) Jurisprudence (2004) 368.

20 See generally the works of Robin West who argues for a 'reconstructive jurisprudence' that 'unmasks the patriarchy behind a purportedly ungendered law'. 
Like the liberal feminist school of thought, radical or dominant feminism focuses on inequality. It asserts that 'men, as a class, have dominated women as a class, creating gender inequality'.21 For radical feminists, gender is a question of power. Radical feminists urge society to abandon traditional approaches that take maleness as their reference point. They argue that sexual equality must be constructed on the basis of woman's difference from man and not be a mere accommodation of that difference. I agree with such an ideological disposition, as society should instead use a more genderneutral and encompassing point upon which to ascertain rights, by using a more egalitarian approach which also does not demean men. Doing so may allow us, within the confines of legal discourse, to achieve an equilibrium of power.

Instead, however, what the court did in Hugo was in fact to accommodate women as being different, not because they are women, but rather that they are perceived as child minders.

The Hugo case, amongst other things, highlights a sharp tension which emerged from the womb of feminist discourse: the ideas of equal treatment and special treatment. The premise under which the 'sameness/different debate' operates is shrouded in the idea that if women need not be treated precisely the same as men, then law should not accommodate women or offer rights unclaimed by men.

What the Hugo case poignantly displays is that the aspiration and conversely unrealistic goal of gender neutrality can and will produce rules and practices making lives worse, not better, for women. That is to say, had women been seen as being the same as men in the Hugo case, the judgment would invariably have been different.

That said, however, the notion of different or special treatment is warranted in light of public policy considerations. Take, for example, arenas in which women face victimisation and need special protections; a battered woman who kills her batterer in his sleep needs a different kind of self-defence defence to the one available to a man who could physically repel his aggressor. ${ }^{22}$

Conversely, such merits must also be tested against postmodernist feminist thinking, which recognises and celebrates that all women can choose as freely as men can. They also, realistically speaking, recognise that women should not always consider themselves 'victims' but are, in fact, capable of free choice in which to leave their abuser and pursue a life of autonomy. Simply put, women's own choices as free autonomous individuals warrant their (1987). 
own change without the presence of an 'alpha male' in which to direct them.

Whilst Hugo serves as authority for the development of South African feminist jurisprudence in its contention regarding women's rights and differential treatment, the following American Supreme Court decision is an example from a foreign jurisdiction as to the perception of women and the law. ${ }^{23}$ In Michael $M v$ Superior Court of Sonoma County, ${ }^{24}$ a teen-age boy challenged a California law which punished any male who had sexual intercourse with a female under age 18 , but not vice versa. The majority decision rejected the challenge by asserting that men and women are not in an equal position in the context of sexual intercourse and child bearing, allowing each group to be treated differently.

In this case, the court's contention was centred on the deterrence of teen pregnancy, which they argued 'supplied a sufficient rationale for the law'. It was contended by the court, therefore, that females have the deterrent of the risk of pregnancy; the criminal penalty imposed solely on males roughly serves to equalise the deterrents on the sexes. Thus, as was the case in Hugo, the female litigant was not treated as different because of her sex or gender, but rather because of the risk of teen pregnancy which is burdensome to government's social welfare and, arguably, to society in general.

However, I believe that what the court did in handing down such a judgment, shrouded under the cloak of under-age women's best interest, is the presumptuous act of assuming that in sexual relations between two persons under the age of 18 , it is the male who is always the aggressor. This implies that only men or boys are capable of inflicting harm. This once again highlights my assertion made with reference to Hugo, that, whilst patriarchal values are endemic in society, such judgments seek to do nothing but further entrench misconceptions and the carnivorous image of society about men and the stigmatisation of women and society's hapless victims. ${ }^{25}$

In this way, I contend that whilst women are crippled by this distinction on the basis of their maternal and biological capabilities, thereby confining them to subordinate roles in all areas of public life, the redress of such unequal rights must not begin through the process of 'penalising' men for quite simply being men. In this way, the distinction that was made in the Hugo case frustrates society as a whole and not just a particular gender group, as it prevents both genders from demolishing the ideological and sociological barriers of

'Feminist legal theories' http://cyber.law.harvard.edu/bridge/CriticalTheory/ critical3.txt.htm (accessed 28 June 2007). 450 US 464 (1981).

This is consistent with liberal feminism which asserts that such gender differences have built up over time and are embedded in culture. 
sex and gender stereotypes which is characteristically an attribute of postmodernist feminist jurisprudence.

Moreover, if courts in their adjudication of equality disputes seek to redress women's rights, this is invariably at the cost of both males and females - as women are not seen as individuals who ought to be provided with equal rights generally, but rather that they should be allowed rights because of their capacities, (as elucidated in Hugo), as child bearers.

Thus, I agree with Kriegler J's minority judgment, in which he saliently expresses the voice behind this paper, that: 'constitutionally the starting point is that parents are parents' ${ }^{26}$

\section{The duality of idealism and paradox of femininity}

However, the notion of sameness, meaning that women wish to be treated the same as men, becomes increasingly difficult when differentiation is made 'along the lines of race, ethnicity, disability, sexual orientation, class, and religion, and other potential lines'. 27

Take, for example, a woman from orthodox and conservative Iran. According to feminists, women should be treated the same as men, however, cultural and religious ideology prevent such women from ever engaging in the sphere of traditional male activities. ${ }^{28}$

It has been submitted, therefore, 'that for many of these women, the solution is not to dispense with the customary systems but to develop them in accordance with principles which affirm women, at the same time ... legal rights are addressed'. 29

Thus, the point that needs to be made is that the feminist contention of 'sameness' is often unrealistic and ill-considered when weighed against cultural and social discrepancies around the world. Ultimately, the values of traditional western liberal feminist jurisprudence, characterised by democratic establishments, fall short when used in developing states where democracy, let alone transient civil rights, are nothing more than an ideal.

It is submitted that the path upon which feminists should walk is a post-modern one, whose 'signs' are unclear and roads unpaved ensuring that, as intellectual thought based upon the premise of questioning becomes more apparent, the women who travel on such

26 Hugo (n 1 above) para 85.

n 22 above.

Mainstream media has taken the testaments of Islamic women as revealing the inner workings of an inherently patriarch dominated sociological and theological framework.

29 Albertyn (n 4 above) 317, who refers to R Coomaraswamy 'To bellow like a cow: Women, ethnicity and the discourse of rights' in R Cook (ed) Human rights of women: National and international perspectives (1994) 39. 
a path are clear that their rights should not be seen as proportionate to and on par with men. ${ }^{30}$ Rather, they should identify experiences and modes of self-actualisation which lend meaning to their own subjective experiences, thereby creating a way of identifying who they are and what it truly means to be a woman.

Postmodernism as a discourse realises that, because we all see out of different eyes, and have no way of knowing that we even see the same 'colours', let alone the same reality, there can be no truly objective 'reality'. All reality is filtered through individual senses, which render sensory experiences subjective. Such a mode of thinking, therefore, highlights internal inconsistencies within feminist (legal) discourse and therefore refutes possible constructions which have become coherent.

In this way, women should be treated differently, but not so differently that it prejudices men's rights; but to the extent that it will highlight the need of recognising their own subjective experiences as defining their own reality and what it means for them within a given social, political and thus legal context to be truly a woman.

One of the core premises of post-modern thought is that the self and 'reality' are all constructions. ${ }^{31}$ If my 'self' can be reinvented as often as I wish, then I do not want to limit my options now. I might want to change my mind later.

That said, postmodernism has also grappled with the 'contradictions between theoretical approaches' which threaten to deconstruct and invalidate categorical constructions of women versus the 'political (establishment) which has sought to maintain this'.32

Thus, if the focus is then shifted away from women's rights in relation to that of their male counterparts, women in society are therefore encouraged to concentrate much more upon the ideological self and thus the construction of their identities, which then may have the consequent effect of re-evaluating the societal standards and expectations of traditional female roles.

It is submitted that it would be a mistaken assumption to treat all women as having the same interests, identities, needs and values, especially since doing so tends to privilege the preferences and viewpoints of privileged white women who are in the position to assert their rights free from theological and sociological constraints, ironically, often to the exclusion of our fictional Iranian woman

30 This seems hardly allegorical to arguments of gender oppression being 'a source of unity among women'.

31 Such an assertion is similar to that of proponents of Critical Race Theory who also contend that race, like gender, are all constructions supported by society for the purposes of categorically developing universal values and norms.

32 Albertyn (n 4 above) 300. 
above. Thus, 'concrete identities are constructed in psychological, social and political contexts - they are in psychoanalytical terms, the outcome of a situated desire of the other'.33

Such a position therefore necessitates that we reconsider the communitarian ideal of relativism and thus the 'possibility of universal values and human rights'. More importantly, however, what must be redressed are the 'norms across cultural difference' and the 're-engaging of transnational conversations about law, feminism and social change'. 34

Postmodernism within legal discourse is highly sceptical of explanations, which claim to be valid for all groups and cultures, traditions or races. What should have been done in terms of the Hugo judgment is to focus on the relative truths of each person, ${ }^{35}$ or specifically each woman as opposed to categorically placing them as one, all with the same mothering capabilities and interests in pursuing a life, which focuses upon the family. In doing this, such a methodology obviates the effect of reinforcing the patriarchal stereotype as each woman then is seen to be an individual disassociated from the class-based society of which she emanates.

In closing, it is submitted that what should be established, as subtly purported by Kriegler $\mathrm{J}$, is a rational mode of analysis that uses men and women, of all kinds of socio-political and demographic backgrounds, as the starting point of analysis and consequently developing rules for workplaces, families, politics and society which are fully inclusive. ${ }^{36}$ In doing so, it would enable us to meet not only our constitutional obligations but also end an era of relegation and subservience upon which equality is made the dominant ideology. (2005) 195.

34 Albertyn ( 4 above) 317, in referring to $M$ Nanda 'Do the marginalised valorise the margins: Exploring the dangers of difference' in K Saunders (ed) Feminist post-development thought (2002).

35 Albertyn ( 4 above) 293 , in referring to $S$ Dahl 'Taking woman as a starting point: Building women's law' (1986) 14 International Journal of Sociology of Law 239. 